i-DUST 2010, $02002(2011)$

DOI: $10.1051 /$ idust/201102002

(C) Owned by the authors, published by EDP Sciences, 2011

\title{
The Hermanus Magnetic Observatory as a space physics facility
}

\author{
D.J. Gouws ${ }^{\mathrm{a}}$, E.F. Saunderson ${ }^{\mathrm{b}}$, and L.A. McKinnell \\ Hermanus Magnetic Observatory, Hospital Street, Hermanus, South Africa
}

\begin{abstract}
The Hermanus Magnetic Observatory (HMO) is an Earth and Space national research facility in Southern Africa. It forms part of a worldwide network of observatories and data centres and is also the space weather Regional Warning Centre (RWC) for Africa under the International Space Environment Service (ISES). In this context, the HMO conducts research, makes observations and models the variations of the Earth and space environments using a wide network of instruments that are spread around the Southern African region and extending as far south as Antarctica. In addition, the HMO offers technological services to the public and commercial clients in the defense, aerospace and maritime industries. The HMO also runs a Science Outreach program for the advancement of science amongst learners, educators and the general public.
\end{abstract}

\section{INTRODUCTION}

The Hermanus Magnetic Observatory (HMO) is located close to the Southern tip of Africa, and has been operating continuously as a magnetic observatory at this location since 1941. However, the activities at the HMO entail far more than at the average magnetic observatory.

\section{THE HMO AS AN INTERMAGNET MAGNETIC OBSERVATORY}

The primary objective of magnetic observatory operations internationally is to make uninterrupted accurate measurements of the Earth's magnetic field over decades at a stable and magnetically clean location. This is required to track the slow variation of the field generated in the Earth's fluid outer core. The HMO has been making these measurements of the Earth's magnetic field at the same magnetically clean location in Hermanus, South Africa, since 1941. Geomagnetism research activities at the HMO is centered around monitoring and studying variations of the Earth's magnetic field, the derivation of geomagnetic field models and indices, and the distribution of geomagnetic field information. In order to record geomagnetic field variations, magnetometers are operated on a continuous basis at the HMO's four INTERMAGNET observatories at Hermanus, Hartebeesthoek, Tsumeb (Namibia), and Keetmanshoop (Namibia). The data are then processed in accordance with INTERMAGNET standards. A map of all INTERMAGNET observatories is shown in Figure 1. The processed data are distributed to a number of international agencies, such as the World Data Centers (WDC) in Kyoto, Japan, and Boulder, USA, in order to facilitate access by researchers and to be utilised for the computation of geomagnetic indices.

At Hermanus 2 FGE magnetometers (three-axis suspended fluxgate magnetometer Model FGE), a dIdD (Delta Inclination Delta Declination) suspended Overhauser magnetometer, and a standalone

\footnotetext{
a e-mail: dgouws@hmo.ac.za

b e-mail: esaunderson@hmo.ac.za

This is an Open Access article distributed under the terms of the Creative Commons Attribution-Noncommercial License 3.0, which permits unrestricted use, distribution, and reproduction in any noncommercial medium, provided the original work is properly cited.
} 


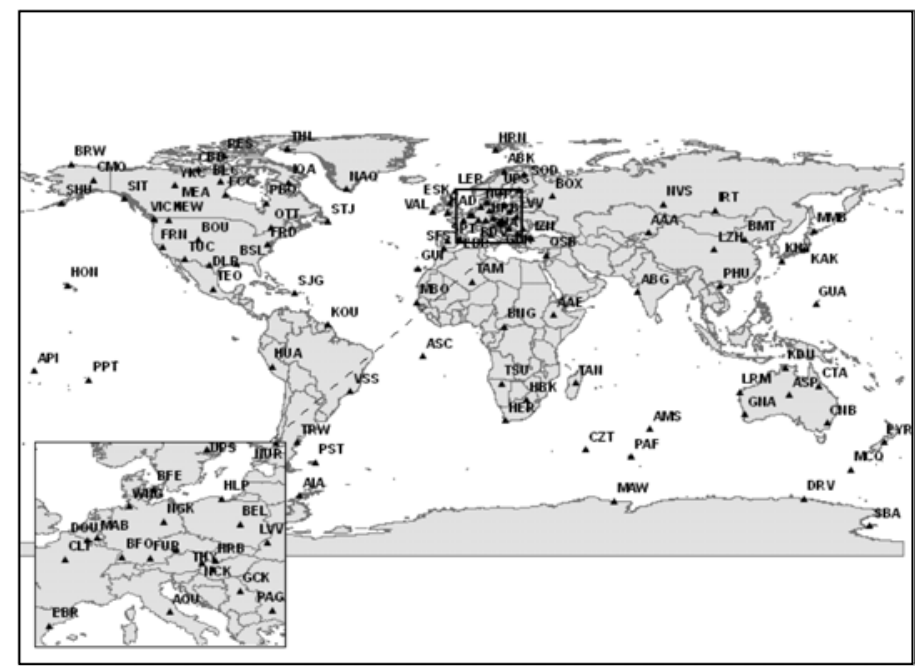

Figure 1. A map of INTERMAGNET observatories.

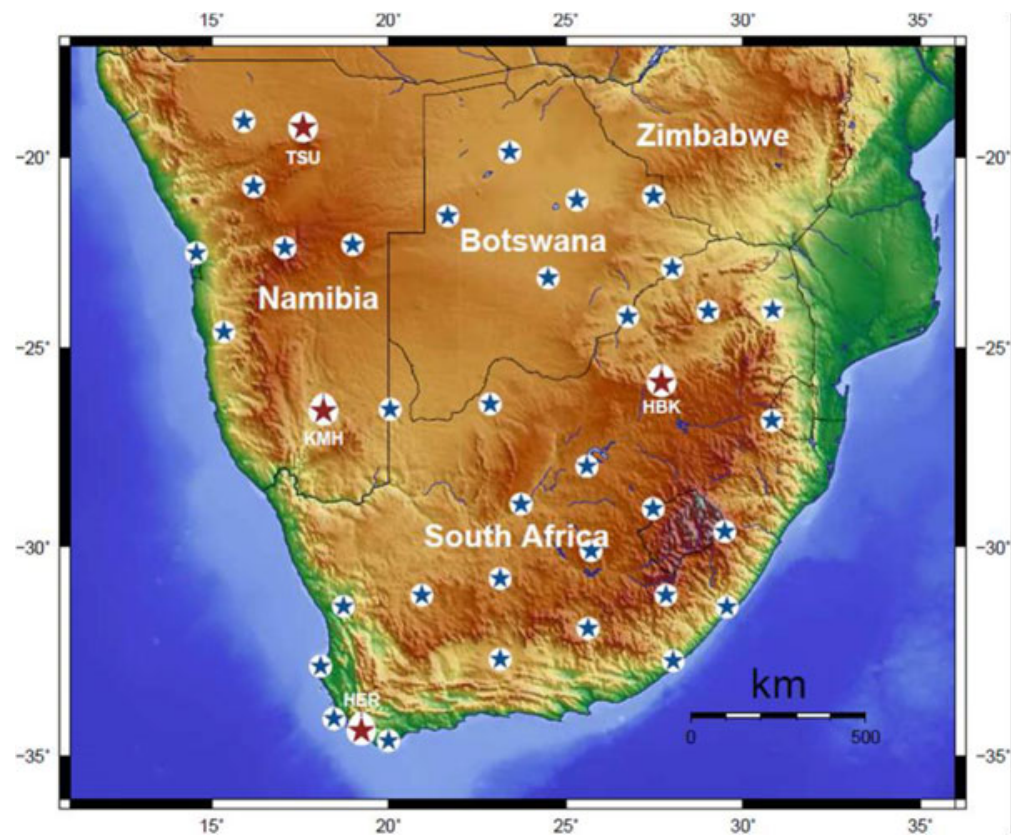

Figure 2. Location of the 4 INTERMAGNET observatories, Hermanus (HER), Hartebeesthoek (HBK), Keetmanshoop (KMH) and Tsumeb (TSU), as well as the secular variation field stations.

scalar Overhauser magnetometer are continuously recording geomagnetic data. At each of the other three observatories an FGE three-axis fluxgate magnetometer and scalar Overhauser magnetometer are in operation. In addition, data from 40 secular variation field stations distributed over southern Africa, including countries like Namibia and Botswana, are recorded annually and used to derive and model the time varying characteristics of the geomagnetic field for southern Africa [1-3]. Figure 2 shows the distribution of the HMO's four magnetic observatories as well as the field stations. Data from two 


\section{D.J. Gouws et al.: The Hermanus Magnetic Observatory as a space physics facility}

low Earth orbit (LEO) magnetic field satellites, namely, the Danish Ørsted and the German CHAMP satellites, are used to supplement the above mentioned ground data for the derivation and updating of geomagnetic field models [4]. These models are used to provide accurate and up-to-date magnetic field information for navigation purposes as required by the South African Defense Force for safety and security as well as peacekeeping missions in Africa. Other clients include, mining companies for mineral exploration, SADC airports, as well as agencies such as ATNS who are responsible for air traffic safety at national airports.

The Earth's magnetic field is presently decreasing at a phenomenal rate; at the current rate the dipole field will vanish within one thousand years, which is ten times faster than the natural decay after a complete switch-off of the geodynamo. The rapidly decreasing field has evoked the suggestion that a reversal of the geomagnetic field may have commenced. Two prominent patches of reverse magnetic polarity have been identified at the core/mantle boundary, which can account for almost all of the present-day decrease. The most intense reverse patch is beneath the southern tip of Africa (South Atlantic Magnetic Anomaly) [5]. Since the establishment of the HMO in Hermanus in 1941, the total field intensity has decreased by $20 \%$, which is greater than the decrease at any other magnetic observatory. The Southern African subcontinent is therefore an ideal location for studying the processes responsible for both the regional and global changes of the geomagnetic field. The four South African observatories are thus strategically positioned geographically within the world to monitor and study important geomagnetic changes. The HMO also has particular significance because of its contribution to the DST (Disturbance Storm Time) ring current index, as the Hermanus Observatory is one of only 4 global observatories contributing to the calculation of this index.

The HMO operates a 3 axis induction sensor as well as a 3 axis MAGDAS (MAGnetic

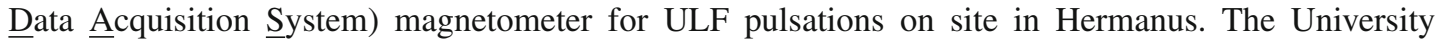
of California, Los Angeles (UCLA), installed a pulsation fluxgate magnetometer in Tsumeb in collaboration with $\mathrm{HMO}$, and the HMO has full access to all the data from pulsation magnetometers operated by UCLA worldwide. The HMO also operates a 12NM64 neutron monitor on site at Hermanus. The HMO employs 35 members of personnel.

\section{SPACE PHYSICS RESEARCH}

The current areas of research within the field of space physics undertaken by the HMO include specialisation in areas of geomagnetism, atmospheric physics, ionospheric physics, magnetospheric physics and space plasmas. The research topics are varied and include studies on the variation of the Earth's geomagnetic field and its applications to navigation; the propagation of waves in the various regions of the space environment, their effects and diagnostic information on the propagation media; ionospheric characterisation; space weather in a basic and applied sense; space plasmas; and radio wave propagation. The approaches are both experimental and theoretical.

Some key questions under research at the HMO are:

- How the anomalous secular variation pattern of southern Africa relates to the evolution of the South Atlantic Magnetic Anomaly which is dominated by a region of reverse flux at the CoreMantle Boundary.

- How do waves result in the vertical coupling of the lower atmosphere to the middle and upper atmosphere?

- To what extent does a non-thermal velocity distribution for the ions determine the existence of positive potential solitary waves and positive potential double layers in a dusty plasma composed of both negative and positive dust grains?

- Pulsations manifest themselves in various geophysical data sets with varying levels of usability. Current research focuses on extracting usable pulsation information from all these data sources and using the data to study the magnetospheric configuration. 
i-DUST 2010

- What are the effects of ionospheric dynamics, structure and variability on man's technological systems?

- What are the drivers and mechanisms of Southern Hemisphere mid-latitude ionospheric scintillations at GPS frequencies? This is a first and essential step in the modelling of mid-latitude ionospheric scintillations which will enhance the ability to predict such space weather events.

- A key objective of current research is to improve the understanding of the sources and mechanisms responsible for low-latitude Pc3 geomagnetic pulsations, which serve as a powerful space weather diagnostic.

\section{OBSERVATIONAL AND MONITORING INSTRUMENTATION}

In collaboration with its national partners (NWU, UKZN, Rhodes, CDSM), the HMO owns and/or operates a wide suite of earth-space observational and monitoring instrumentation which include various types of magnetometers, ionosondes, an HF radar, ionospheric scintillation and TEC monitors, neutron monitors, imaging riometer, broad-beam riometer, low light auroral video cameras, GPS receivers, WWLLN lightning detectors, VLF receivers and a whistler detector. These instruments are located in various locations including South Africa, Namibia, Marion Island, Gough Island and the South African Antarctic base SANAE-IV.

Through this geographically wide and multi-functional observational network, the HMO contributes earth and space data to various global networks including:

- the International Real-time Magnetic Observatory Network (INTERMAGNET),

- Digital Ionogram DataBase (DIDBase),

- Global Assimilative Ionospheric Model (GAIM),

- Super Dual Auroral Radar Network (SuperDARN),

- World Wide Lightning Location Network (WWLLN) and

- International Polar Year Data and Information Service (IPYDIS).

The HMO provides a research platform for the earth-space system for South Africa, Africa and international collaborators through the creation, maintenance and operation of this wide observational network and the associated high-tech data repository and distribution network.

\subsection{Space weather}

The HMO operates as the space weather Regional Warning Centre (RWC) for Africa under the International Space Environment Service (ISES). ISES's mission is to encourage and facilitate nearreal-time international monitoring and the prediction of the space environment as well as to assist users to reduce the impact of space weather on activities of human interest, e.g. the protection of satellite technology and HF communication predictions. The space weather operations facility at the HMO integrates all data sets with a full space weather warning and prediction service. This includes a realtime warning service to clients as well as a daily long-term prediction service of $\mathrm{S}_{\mathrm{e}}-\mathrm{T}, \mathrm{Ap}$ and $\mathrm{Q}_{\mathrm{fe}}$ indices and space weather forecasts for use by clients as well as researchers.

The HMO operates a state-of-the-art digital ionospheric radar, model Digisonde DPS-4D on site in Hermanus. The HMO is also responsible for the maintenance, operation, data archiving and distribution of 15 minute ionospheric data of the other three Lowell ionosondes in South Africa located at Grahamstown (Eastern Cape), Madimbo (Limpopo) and Louisvale (Northern Cape).

Figure 3(a) shows an example of ionospheric data in the form of an ionogram measured from an ionosonde located in Grahamstown. An ionosonde is an instrument that transmits a swept frequency signal vertically and analyzes the reflection of this signal from the ionosphere. This ionogram contains a significant amount of information about the state of the ionosphere above the instrument's location. In Fig. 3(a) one can, for example, see that the reflected signal contains two differently polarized 


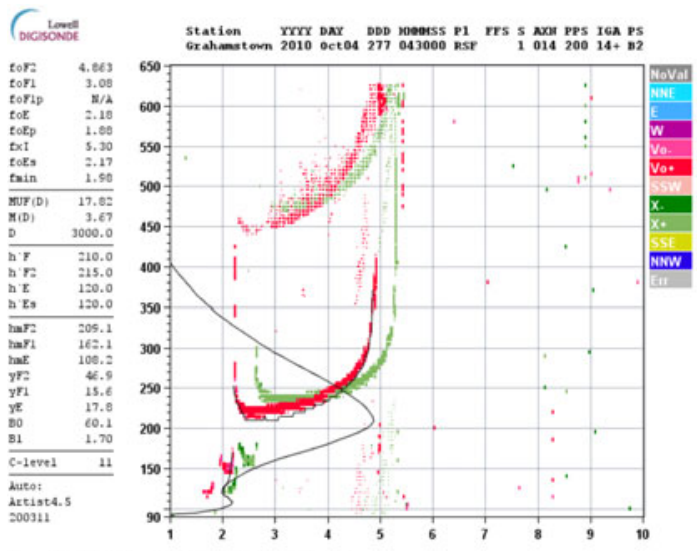

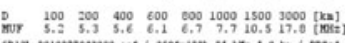

(a)

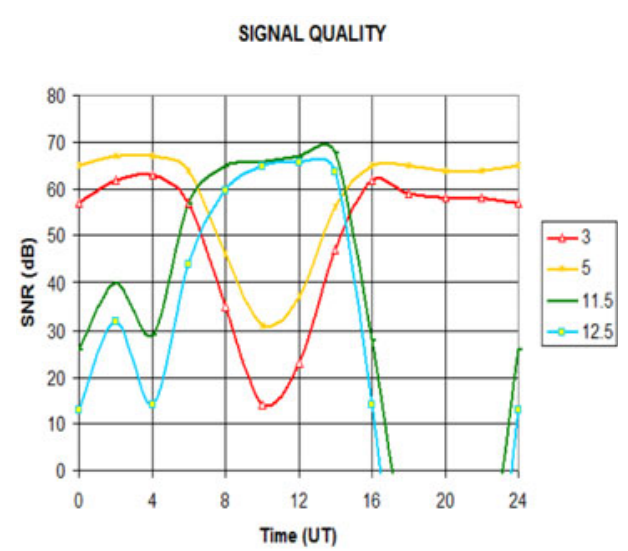

(b)

Figure 3. (a) Ionospheric data; (b) HF communication prediction.

components - the magenta and green traces. It also shows there are clearly two ionospheric layers one at an altitude of just over $200 \mathrm{~km}$ and another at about $130 \mathrm{~km}$. It also shows the ionospheric profile, the various critical frequencies, heights, etc.

Figure 3(b) is an example of an HF frequency prediction for a radio link between two specific locations, and shows the hour of the day on the horizontal axis and the predicted signal to noise ratio at the receiver site for four frequencies on the vertical axis. The line colours identify the frequencies. The user simply has to select the frequency with the highest signal to noise ratio for the time of day that communications has to take place.

The data is supplied in a variety of standard formats and used for research, the determination of key space weather parameters and the simulation, modeling and forecasting of the Earth space environment.

\subsection{Antarctica and the South Atlantic islands}

The HMO is responsible for the technical upkeep and research related to most of the Antarctic projects, measuring and monitoring equipment at the South African Antarctic base SANAE-IV, as well as on the two South Atlantic islands Marion and Gough. The following instruments are all operated by the HMO at SANAE, as well as on the islands when specifically mentioned.

\subsubsection{SANAE SuperDARN Radar}

The Super Dual Auroral Radar Network (SuperDARN) is an international collaborative radar network of HF radars that monitor ionospheric plasma convection over the majority of the northern and southern Polar Regions. SuperDARN is currently comprised of 15 radars in the northern hemisphere and 7 in the southern hemisphere that operate in the High Frequency (HF) bands between 8 and $22 \mathrm{MHz}$. The radars measure the Doppler velocity of plasma density irregularities in the ionosphere. Data from all the radars in the network are combined to form a convection map of the polar ionosphere, to infer the connection between the Earth's magnetosphere and the solar wind. The HMO is involved in the Southern Hemisphere Auroral Radar Experiment (SHARE), with the British Antarctic Survey (BAS), and manages the SHARE radar at SANAE, Antarctica. 


\subsubsection{Overhauser total field magnetometer}

The GSM-19 v7.0 Overhauser instrument is the total field magnetometer/gradiometer of choice in today's earth science environment. With data quality exceeding standard proton precession and comparable to costlier optically pumped cesium units, the GSM-19 is a standard in many fields.

\subsubsection{FGE three-axis vector magnetometer}

The fluxgate magnetometer type FGM-FGE is suitable for digital recording of the magnetic field at observatories and in the field. In order to avoid drift due to tilt of the instrument pier, which is often the main cause of baseline drift, a special version of the magnetometer is available in which the sensors are suspended by two crossed bronze bands to compensate for the tilt. The FGM-FGE magnetometer has analog outputs enabling the user to adapt the instrument to their own data logging systems. The FGM-FGE features 3 linear core sensors mounted on a marble cube for good mechanical stability, compensation coils on quartz base for highest temperature stability and highly stable digitally controlled compensation of the main field.

\subsubsection{Declination-Inclination (DI) observation station}

The DI Flux is a single axis fluxgate magnetometer mounted on a theodolite for the measurement of Declination and Inclination of the geomagnetic field. The D\&I Fluxgate Magnetometer Model G operated by the HMO at SANAE uses a Pandect fluxgate sensor with a low noise giving a digital output stable to $0.1 \mathrm{nT}$ and an initial offset lower than $10 \mathrm{nT}$.

\subsubsection{GPS Ionospheric Scintillation and Total Electron Content Monitor (GISTM)}

Scintillations are naturally-occurring disruptions in the ionosphere that can cause a rapid fluctuation, or scintillation, of satellite signals at or near the Earth's surface. It can cause signal fading or phase gradients which can unlock a GPS receiver or cause poor reception and therefore poor position-line accuracy from the particular satellite [6]. GISTM receivers are operated on Marion as well as Gough islands in addition to the receiver at SANAE.

\subsubsection{SAN Pulsation Magnetometer}

The Pulsation Magnetometer measures rapid $(<1 \mathrm{~Hz})$ fluctuations in the $\mathrm{X}$ and $\mathrm{Y}$ components of the Earth's magnetic field [7]. Data are displayed on a monitor in real time and also stored digitally. The data are used in conjunction with VLF data, quasi-periodic VLF emissions being associated with magnetic pulsations. The instruments are important also for auroral and riometer observations.

\subsubsection{Digital VLF Recording and Analysis System}

A digital broadband VLF recording system DVRAS is operated at SANAE. Broadband VLF data are archived in digital format, facilitating the rapid generation of spectrograms and application of digital filtering techniques for comparisons with experimental data from other sources [8].

\subsubsection{Automatic Whistler Detector}

Whistler times are acquired using the Automatic Whistler Detector (AWD) developed at Eötvös University. The detector identifies the whistler epoch as the time at which the whistler trace passes through $7 \mathrm{kHz}$. Although the detection system has been operational for a number of years, it is still considered to be in an experimental state. 


\section{D.J. Gouws et al.: The Hermanus Magnetic Observatory as a space physics facility}

\subsubsection{WWLLN lightning detector}

The World Wide Lightning Location Network WWLLN determines the location of lightning strikes. Each lightning stroke location requires the time of group arrival (TOGA) from a least 5 WWLLN sensors. These sensors may be several thousand $\mathrm{km}$ distant from the stroke. The geographical arrangement of the sensors is important: a lightning stroke which is enclosed by sensors is much more accurately located than one which is not so enclosed. Recent research indicates detection efficiency for strokes about $30 \mathrm{kA}$ is approximately $30 \%$ globally.

\subsubsection{UltraMSK narrowband VLF Receiver}

UltraMSK (Ultra Minimum Shift Keying) is a VLF radio receiver suitable for use in scientific research applications involving the remote sensing of the ionosphere or magnetosphere. UltraMSK measures both the phase and amplitude of MSK modulated narrowband VLF radio signals [9]. The HMO operates an UltraMSK VLF receiver on Marion Island in addition to the receiver at SANAE.

\subsubsection{AWESOME VLF Receiver}

The AWESOME (Atmospheric weather electromagnetic system for observation modeling and education) Monitor consists of a VLF/ELF antenna, preamplifier box, and a line receiver box. VLF data can be recorded locally and transmitted to a central database. The HMO operates this VLF receiver at SANAE.

\subsubsection{Riometers (Relative Ionospheric opacity meters)}

Riometers are instruments used to quantify the amount of electromagnetic wave ionospheric absorption in the atmosphere [10]. Riometers measure the strength of radio noise originating from stars or galaxies and arriving at the Earth after passing through the ionosphere. The Imaging Riometer for Ionospheric studies (IRIS) is a 64-element matrix arranged in an $8 \times 8$ pattern. Each of the elements is a circularly polarised crossed dipole (turnstile). The matrix covers an area of $200 \times 200 \mathrm{~km}$ at an altitude of 90 $\mathrm{km}$ above the Earth. Electron precipitations, resulting from solar activity, in the ionospheric D and E layers are investigated by examining the absorption of cosmic radio noise from stars in the Milky Way. Dynamic events can be examined by making correlations between signals originating from different directions and detected by the riometer that measures ionospheric absorption of galactic radio noise. Broad beam riometers have a significantly larger angle of operation, whereas the imaging riometers give a much more reliable directional average of an event.

\subsubsection{Low light aurora video camera}

The HMO operates two low light aurora video cameras at SANAE. Auroral imaging devices are low light level video cameras for studying the motion of auroral forms [11]. The Auroral All Sky Camera is particularly used in conjunction with satellite electric field measurements. The objective is to establish what electrical field structures are related to particular auroral forms. We also look for correlations with absorption events measured by the 64-element array riometer.

\section{MAGNETIC TECHNOLOGY SERVICES}

The HMO furthermore utilises the unique magnetic field calibration facilities and infrastructure, located in a magnetically clean environment, to provide quality controlled magnetic field and sensor related 
i-DUST 2010

services to the public and commercial clients in the defense, aerospace and maritime industries on a commercial basis. In general the services include air navigation and navigation ground support, naval system support, magnetic system control and navigation. Specific services to the South African Air force and other aviation industries include compass calibrations, geomagnetic surveys and in-service training of technical ground personnel. Services to the South African Navy include under-water measurement and electrical and magnetic signature management, as well as degaussing and deperming of the Navy fleet. A variety of applications for commercial clients sensing the geomagnetic field is employed in the placement of magnetic sensors on unmanned airframes, integration of magnetic sensors in systems, magnetic calibration and navigation algorithms, magnetic screening and other magnetic evaluations and applications.

The HMO developed and manufactured a scientific magnetometer and an orientation magnetometer for South Africa's first microsatellite SUNSAT. The HMO further manufactures orientation magnetometers under contract from a South African satellite company for international micro-satellites, as well as South Africa's second micro-satellite, SumbandilaSat, that was launched during 2009. Magnetic characterisations of micro-satellites are executed at the HMO in order to obtain magnetic parameters for satellite orientation control.

Equipment and infrastructure used for these services include a large non-magnetic climatic chamber, a large Helmholtz coils system $(2.5 \mathrm{~m})$ for calibration of magnetometers, weapon systems and micro satellites, and a magnetic shielding chamber.

\section{TRAINING, SCIENCE ADVANCEMENT AND OUTREACH}

The HMO presents in-service training of personnel of various clients such as the South African Defense Force in terms of navigation support and space weather. The HMO furthermore presents space science training during a variety of Summer -, Winter - and Antarctic schools and teaching at partner universities, including subjects such as space physics, geomagnetism, aeronomy, electromagnetism, MHD (Magnetohydrodynamic) waves, signal processing and other courses for graduate and post graduate students from various institutions. Approximately $16 \mathrm{MSc}$ and $\mathrm{PhD}$ space physics students live on site at the HMO and undertake their studies under supervision at the HMO, utilizing data from the various instruments managed by the HMO. The HMO also funds approximately 10 other post graduate students based at South African universities, with their supervision shared between the HMO and the universities.

In terms of science advancement and outreach the HMO promotes awareness and interest in science and technology to a broad audience including young people, educators, the general public and policymakers. The HMO has a dedicated Science Centre on site with an emphasis on informal learning. The Science Centre hosts various workshops and learning opportunities for a large number of school learners and Physical Sciences educators from rural areas around Hermanus, thus providing curriculum support. The Science Awareness program promotes Earth and space science and related technologies among educators, learners and the public. The HMO programmes follow an interactive approach aimed at developing science process skills. Activities and events include National Science Week, World Space Week, Science Role Modeling Campaign and International Polar year. Particular activities which are run by HMO Science Centre include satellite building contests, aurora workshops, rocket building and electric motor workshops. The HMO Science Centre engages with about 5000 learners per year.

HMO Science Advancement group engage with the public on a regular basis offering tours and popular scientific talks. The tours are structured to provide visitors with an opportunity to engage with the equipment and services related to a magnetic observatory and space science centre. The HMO space weather centre introduces visitors, learners and educators to a unique science awareness experience in a magnetically clean environment. 
D.J. Gouws et al.: The Hermanus Magnetic Observatory as a space physics facility

\section{References}

[1] M. Korte, M. Mandea, P. Kotzé, E. Nahayo, and B. Pretorius, Improved observations at the southern African geomagnetic repeat station network, South African Journal of Geology 110, 175-186 (2007)

[2] P.B. Kotzé, The time-varying geomagnetic field of Southern Africa, Earth Planets and Space 55, 111-116 (2003)

[3] P.B. Kotzé, M. Mandea, and M. Korte, Modelling the southern African geomagnetic field secular variation using ground survey data for 2005, South African Journal of Geology, 110, 187-192 (2007)

[4] P.B. Kotzé, Spherical cap modelling of Ørsted magnetic field vectors over southern Africa, Earth Planets and Space 53, 357-361 (2001)

[5] M. Korte, M. Mandea, H.-J. Linthe, A. Geese [Hemshorn], P. Kotzé and E. Ricaldi, New geomagnetic field observations in the South Atlantic Anomaly region, Annals of Geophysics, 52, 65-81 (2009)

[6] P. Cilliers, B. Opperman, \& R. Meyer, Investigation of ionospheric scintillation over South Africa and the South Atlantic Anomaly using GPS signals: First results, Geoscience and Remote Sensing Symposium, 2009 IEEE International, IGARSS 2009, IEEE (2010)

[7] K. Sundberg, A. Hughes, A. Collier, P. Eriksson \& L. Blomberg, Magnetic field oscillations at SANAE IV related to sudden increases in solar wind dynamic pressure, South African journal of science 101(11-12), 539-543 (2005)

[8] A. Collier \& A. Hughes, Digital VLF recording and analysis system for Sanae IV, South African journal of science 98(11-12), 547-550 (2002)

[9] M. Clilverd, C. Rodger, N. Thomson, J. Brundell, T. Ulich, J. Lichtenberger, N. Cobbett, A. Collier, F. Menk, A. Sepp \& others, Remote sensing space weather events: the AARDDVARK network, Space Weather 7 (2009)

[10] P. Stoker, Riometer absorption and spectral index for precipitating electrons with exponential spectra, Journal of Geophysical Research 92(A6), 5961-5968 (1987)

[11] P. Stoker \& J. Bijker, Auroral optical emissions related to imaging riometer observations, South African journal of science 101(5/6), 281 (2005) 